\title{
Association of endometrosis in horses with differentiation of periglandular myofibroblasts and changes of extracellular matrix proteins
}

\author{
I. Walter ${ }^{1}$, J. Handler ${ }^{2}$, M. Reifinger ${ }^{3}$ and C. Aurich ${ }^{4}$ \\ ${ }^{1}$ Institute of Histology and Embryology, University of Veterinary Medicine, Veterinärplatz 1, \\ A-1210 Vienna, Austria; ${ }^{2}$ Clinic for Obstetrics, Gynaecology and Andrology, University of \\ Veterinary Medicine, Veterinärplatz 1, A-1210 Vienna, Austria; ${ }^{3}$ Institute of Pathology and \\ Forensic Veterinary Medicine, University of Veterinary Medicine, Veterinärplatz 1, A-1210 \\ Vienna, Austria; and ${ }^{4}$ Center for Artificial Insemination and Embryo Transfer, University of \\ Veterinary Medicine, Veterinärplatz 1, A-1210 Vienna, Austria
}

Periglandular fibrosis and cystic dilation of uterine glands are associated with equine endometrosis. The presence of extracellular matrix proteins (collagen type I, III and IV, laminin and fibronectin) in healthy and endometrotic specimens was demonstrated by immunohistochemistry. The distribution of collagen I, but not collagen III, was dependent on the stage of the oestrous cycle. The arrangement of collagen I and collagen III in endometrotic specimens was similar to that in normal endometrium. In periglandular fibrosis, collagen IV, laminin and fibronectin deposition outside the basement membrane was observed. In these regions, stromal cells were characterized immuno- histochemically as myofibroblasts because of their expression of $\alpha$-smooth muscle actin, and occasionally tropomyosin and desmin. Periglandular differentiation of contractile cells could be interpreted as a reaction to support the extrusion of secretions in cystic dilated glands. Moreover, the changes of extracellular matrix proteins are characteristic for neoplastic lesions, although further development of endometrosis to benign or malignant tumours is not known in horses. Knowledge of the factors responsible for these fibroblastic modulations may be the key to explaining the pathogenesis of endometrosis.

\section{Introduction}

Endometrosis, one of the most frequent reasons for infertility in horses, is a chronic degenerative endometrial disease involving severe alterations in the uterine connective tissue and glands. Kenney and Doig (1986) introduced a classification system to discern four groups, from animals with normal endometrium to animals with severe pathological alterations (I, IIA, IIB and III), which is still in use. Prognosis for successful breeding is detrimental for horses classified as categories IIB and III. However, endometrosis can only be diagnosed by histological examination of a uterine biopsy sample. Histological changes associated with endometrosis include formation of fibrotic and dilated glands or glandular nests. The affected glands are reported to differentiate irregularly during the oestrous cycle (Schoon et al., 1997) and it has been shown by lectin histochemistry that uterine secretions are also altered (Walter et al., in press).

Although the pathogenesis of this disease is still unknown, it has been established that the extent of these alterations is associated with age of the affected animal (Schoon et al., 1997). It is likely that the equine endometrium undergoes cyclic remodelling of the connective tissue

Email: Ingrid.Walter@vu-wien.ac.at extracellular matrix (ECM) as observed in cows (Kaidi et al., 1991; Boos, 1994) and other species, including humans (Aplin et al., 1988; Stenback, 1989; Goranova et al., 1993). There are no data on the presence and distribution of different types of collagen in the uterus of healthy mares and in those affected by endometrosis. However, various studies on cell-ECM interactions have revealed that the ECM is a source for signals that are capable of influencing growth and differentiation of different types of cell (Bissell et al., 1982). Fibroblastic cells play an essential role in the synthesis and regulation of extracellular connective tissue components and are involved in the pathogenesis of fibrotic processes. During pathogenesis, fibroblastic cells express a range of muscle differentiation factors, such as $\alpha$-smooth muscle actin, tropomyosin and desmin, and were, therefore, identified as myofibroblasts (Sappino et al., 1990; Schmitt-Gräf et al., 1994). Myofibroblasts express various ECM proteins such as fibronectin, laminin, collagen type IV and tenascin (Berndt et al., 1994; Hanamura et al., 1997). It has been suggested that these ECM proteins could be important for the remodelling of neoplastic tissues, as many studies have demonstrated overexpression of fibronectin in carcinomas (Koukoulis et al., 1993; Pujuguet et al., 1996).

The aim of the present study was to elucidate the presence and distribution of ECM proteins (collagen type I, 
Table 1. Primary antibodies used in immunohistochemistry

\begin{tabular}{|c|c|c|c|c|}
\hline Antibody & Type of antibody & Dilution & $\begin{array}{l}\text { Total concentration } \\
\text { of protein }\left(\mu \mathrm{g} \mathrm{ml}^{-1}\right)\end{array}$ & Source \\
\hline Anti-collagen I & Monoclonal & $1: 500$ & $\mathrm{NI}$ & Sigma \\
\hline Anti-collagen III & Monoclonal & $1: 25$ & 40.0 & Quartett \\
\hline Anti-collagen IV & Monoclonal & $1: 25$ & $\mathrm{NI}$ & Quartett \\
\hline Anti-laminin & Polyclonal & $1: 500$ & 8.4 & Dako \\
\hline Anti-fibronectin & Affinity isolated & $1: 1000$ & 0.5 & Sigma \\
\hline $\begin{array}{l}\text { Anti- } \alpha \text {-smooth } \\
\text { muscle actin }\end{array}$ & Monoclonal, clone 1A4 & $1: 200$ & 39.0 & Dako \\
\hline Anti-tropomyosin & Monoclonal, clone TM311 & $1: 4000$ & 6.0 & Sigma \\
\hline Anti-desmin & Monoclonal, clone DE-U10 & $1: 100$ & 233.0 & Sigma \\
\hline
\end{tabular}

NI: not indicated by manufacturer.

III and IV, laminin and fibronectin) in the equine endometrium during the oestrous cycle by immunohistochemical methods in both healthy and affected animals. In addition, morphological and histochemical characteristics of fibroblastic cells surrounding altered (fibrotic and dilated) uterine glands were examined. Further immunohistochemical characterization of periglandular fibroblastic differentiation was accomplished by using antibodies against $\alpha$-smooth muscle actin, tropomyosin and desmin.

\section{Materials and Methods}

\section{Animals}

Uterine biopsy samples were collected from 50 mares (5-23 years of age) of various breeds (Haflinger: $n=8$; Warmblood: $n=20$; Trotters: $n=4$; Thoroughbred: $n=4$; Noriker: $n=14$ ) at different stages of the oestrous cycle. Tissue (one biopsy per animal) was obtained transcervically from the proximal region of the right uterine horn using routine techniques. The stage of the oestrous cycle was determined clinically (transrectal palpation, ultrasonography, control of oestrous behaviour with a stallion) and by determination of plasma concentrations of oestrogen and progesterone according to Behrens et al. (1993). The reproductive stages in the animals examined were as follows: seasonal anoestrus, $n=12$; oestrus, $n=14$; and dioestrus $n=24$.

\section{Histology}

Biopsy samples were either snap frozen in liquid nitrogen (cryosections) or fixed in $4 \%(\mathrm{v} / \mathrm{v})$ neutral formaldehyde for $24 \mathrm{~h}$ at room temperature (paraffin wax sections). After fixation, specimens were dehydrated and embedded in Paraplast ${ }^{\circledR}$ using automated embedding equipment (Tissue Tek V.I.P. 2000, Miles Scientific, Mishawaka). Serial sections were cut at $4 \mu \mathrm{m}$, placed on poly-L-lysine-coated glass slides and dried at $53^{\circ} \mathrm{C}$ overnight. Cryosections were cut at $8 \mu \mathrm{m}$, dried onto glass slides coated with TESPA (3-aminopropyldiethoxysilane, Sigma Chemicals, Vienna) and fixed in ice-cold acetone for 10 min before use.

Biopsy samples were categorized for the grade of endometrosis according to Kenney and Doig (1986) in haemotoxylin and eosin stained sections. Out of 50 mares, $n=13(26 \%)$ were classified as endometrosis grade I or I-IIA; $n=17(34 \%)$ as IIA; $n=10(20 \%)$ as IIA-IIB; and $n=10(20 \%)$ as IIB-III.

\section{Immunohistochemistry}

Paraffin wax sections were rehydrated and peroxidase activity was inhibited by $0.3 \%(\mathrm{v} / \mathrm{v}) \mathrm{H}_{2} \mathrm{O}_{2}$ in methanol. The sections were washed in tap water, mounted with PBS in coverplates $^{\circledR}$ and put into an immunostaining centre (Sequenza, Shandon, Pittsburgh). After 5 min of washing, slides were treated with $1.5 \%(\mathrm{v} / \mathrm{v})$ normal goat serum for $20 \mathrm{~min}$ at room temperature before incubation with the primary antibody overnight at $4{ }^{\circ} \mathrm{C}$. The antibodies used and their final concentrations are summarized (Table 1). On the subsequent day, slides were washed in PBS and incubated either with a fluorescein-conjugated secondary antibody (Alexa ${ }^{\mathrm{TM}} 488$, Molecular Probes, Leiden) or EnVision $+^{\mathrm{TM}}$ (anti-rabbit or anti-mouse immunoglobulins conjugated to peroxidase-labelled dextran polymer; DAKO, Glostrup) for $30 \mathrm{~min}$ at room temperature. In the case of fluorescence detection, slides were counterstained with propidium iodide ( $2 \mu \mathrm{l}$ per $50 \mathrm{ml}$ in distilled water for $5 \mathrm{~min}$ ), washed in distilled water and mounted with Mowiol 4-88 (Hoechst, Frankfurt) n-propylgallate (Sigma). In the case of the EnVision $^{\mathrm{TM}}$ method, sections were washed with PBS and peroxidase activity was detected using DAB substratum (10 mg 3'3 diaminobenzidine in $50 \mathrm{ml}$ of $0.1 \mathrm{~mol}$ Tris buffer $\left.\mathrm{I}^{-1}, \mathrm{pH} 7.4\right)$ and $0.03 \%(\mathrm{v} / \mathrm{v}) \mathrm{H}_{2} \mathrm{O}_{2}$ for $10 \mathrm{~min}$ at room temperature. Thereafter, sections were counterstained with haemalumn, dehydrated and mounted with DPX (Fluka).

Protease pretreatment (protease from Streptomyces griseus, Sigma; $0.1 \%(\mathrm{w} / \mathrm{v})$ in $0.05 \mathrm{~mol}$ Tris buffer $\mathrm{I}^{-1}$, at $\mathrm{pH}$ 7.2 , for $5 \mathrm{~min}$ at $37^{\circ} \mathrm{C}$ ) was necessary for immuno- 
histochemical demonstration of collagen IV, laminin and desmin. Pepsin digestion (Sigma; $0.1 \%(\mathrm{w} / \mathrm{v}$ ) in $0.5 \mathrm{~mol}$ acetic acid $\mathrm{I}^{-1}$ ) for $2 \mathrm{~h}$ at $37^{\circ} \mathrm{C}$ was accomplished before immunostaining of collagen I and III. Hyaluronidase pretreatment (Sigma; 0.016\% (w/v) in PBS, pH 6.7, for $4 \mathrm{~h}$ at $37^{\circ} \mathrm{C}$ ) was performed before immunostaining of fibronectin.

Cryosections were used for immunohistochemical demonstration of collagen I. Control sections were treated with PBS instead of primary antibody, or with unspecific mouse or rabbit IgG from normal serum applied in the same protein concentration as the primary antibody. Fluorescein labelled sections were evaluated using a confocal laser scanning microscope (Leica TCS-NT, Heidelberg).

\section{Results}

Immunohistochemical demonstration of collagen I, III and IV

The normal equine endometrium contains collagen type I fibres that are distributed uniformly in the lamina propria and the arrangement of these fibres is dependent on the stage of the oestrous cycle. In the proliferative phase, collagen type I fibres were thick and distributed loosely in the connective tissue (Fig. 1a). Fibres in the subepithelial stratum compactum were densely arranged. During the secretory phase, collagen type I fibres were tightly packed in all regions of the lamina propria (Fig. 1b). In contrast to collagen I, distribution of collagen type III fibres was not affected by the stage of the oestrous cycle and a dense network of fibres was constantly present in the endometrial connective tissue (Fig. 1c). The arrangement of collagen I and III in endometrotic tissue was similar to that in normal endometrium, but only single glandular nests with diminished collagen III content were observed (Fig. 1d).

In normal endometrium, collagen IV was restricted to the basement membrane of uterine glands and blood vessels (Fig. 1e). Severe fibrosis around the glandular nests was combined with divergent distribution of collagen IV. The multiple layers of fibrocytes surrounding these glands were observed to deposit collagen IV (Fig. 1f). In addition, cystic dilated glands were surrounded by collagen IV-producing fibrocytes in the case of fibrosis; however, this was not the case for nonfibrotic altered glands. Laminin, another component of the basement membrane, had a similar distribution pattern to that described for collagen IV in normal endometrial tissue (Fig. 1g). In cases of severe fibrosis (category IIB-III), laminin was found outside the basement membrane of uterine glands (Fig. 1h). Distribution of collagen IV and laminin was not dependent on the stage of the oestrous cycle.

\section{Immunohistochemical characterization of stromal cells in endometrotic tissue}

Fibroblasts surrounding fibrotic uterine glands frequently showed strong immunoreactivity for anti- $\alpha$-smooth muscle actin (Fig. 2a-f). Distribution patterns of cells positive for $\alpha$ smooth muscle actin in endometrotic tissue were extremely
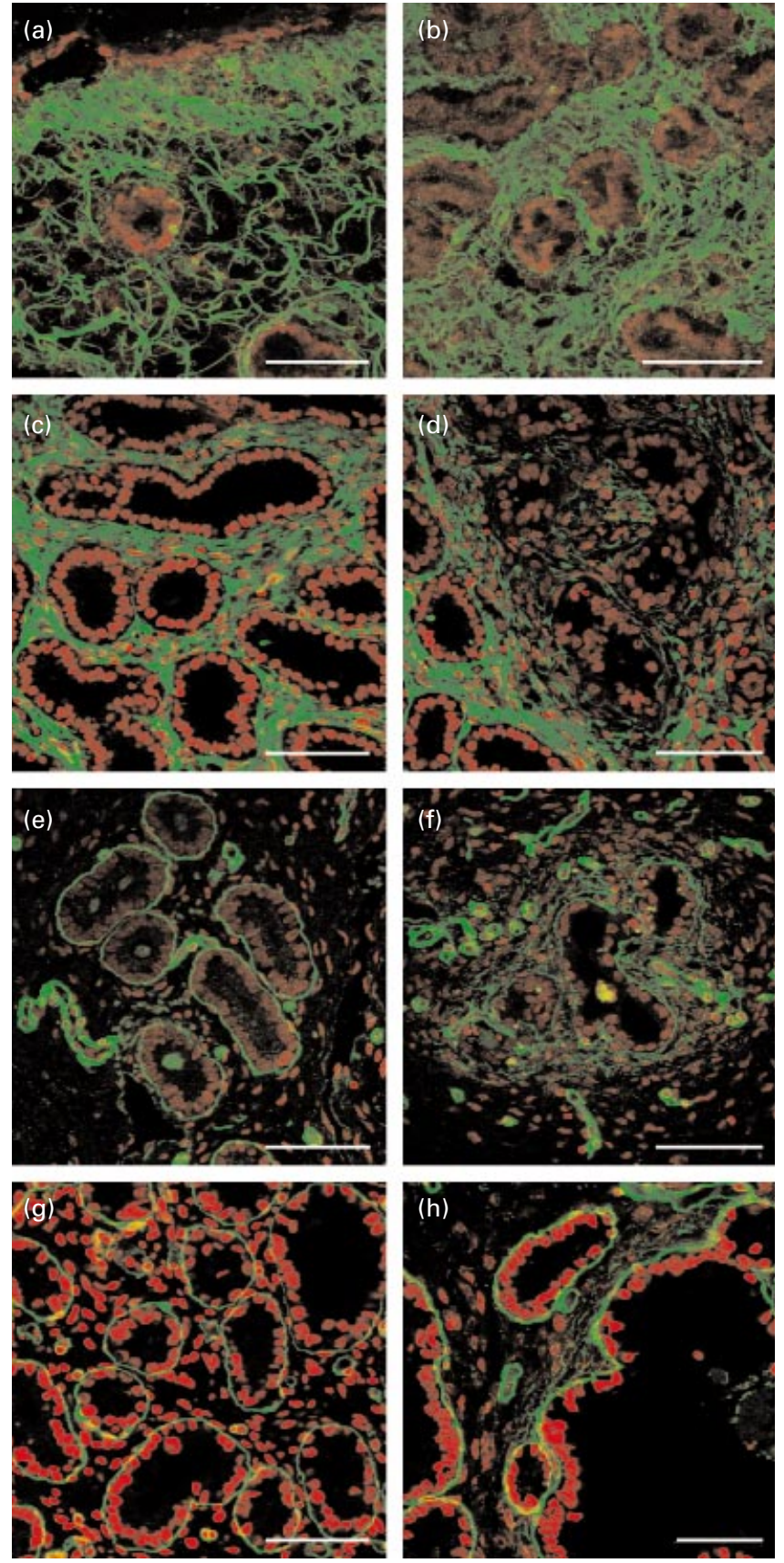

Fig. 1. Immunohistochemical demonstration of collagen type I in the equine endometrium in proliferative (a) and secretory (b) stages of the oestrous cycle. (c) Distribution of collagen type III in normal endometrium. (d) Loss of collagen III fibres was observed in fibrotic glandular nests. (e) Collagen type IV in normal horse endometrium was restricted to the basement membrane of uterine glands and blood vessels. (f) In glands with fibrosis, collagen IV was also deposited by surrounding fibrocytes. (g) Immunohistochemical staining of laminin marked basement membranes in the normal horse endometrium. (h) In addition to the basement membranes, laminin was observed around fibrocytes that were close to altered glands in endometrotic specimens. All sections were counterstained with propidium iodide. Scale bars represent $50 \mu \mathrm{m}$. 

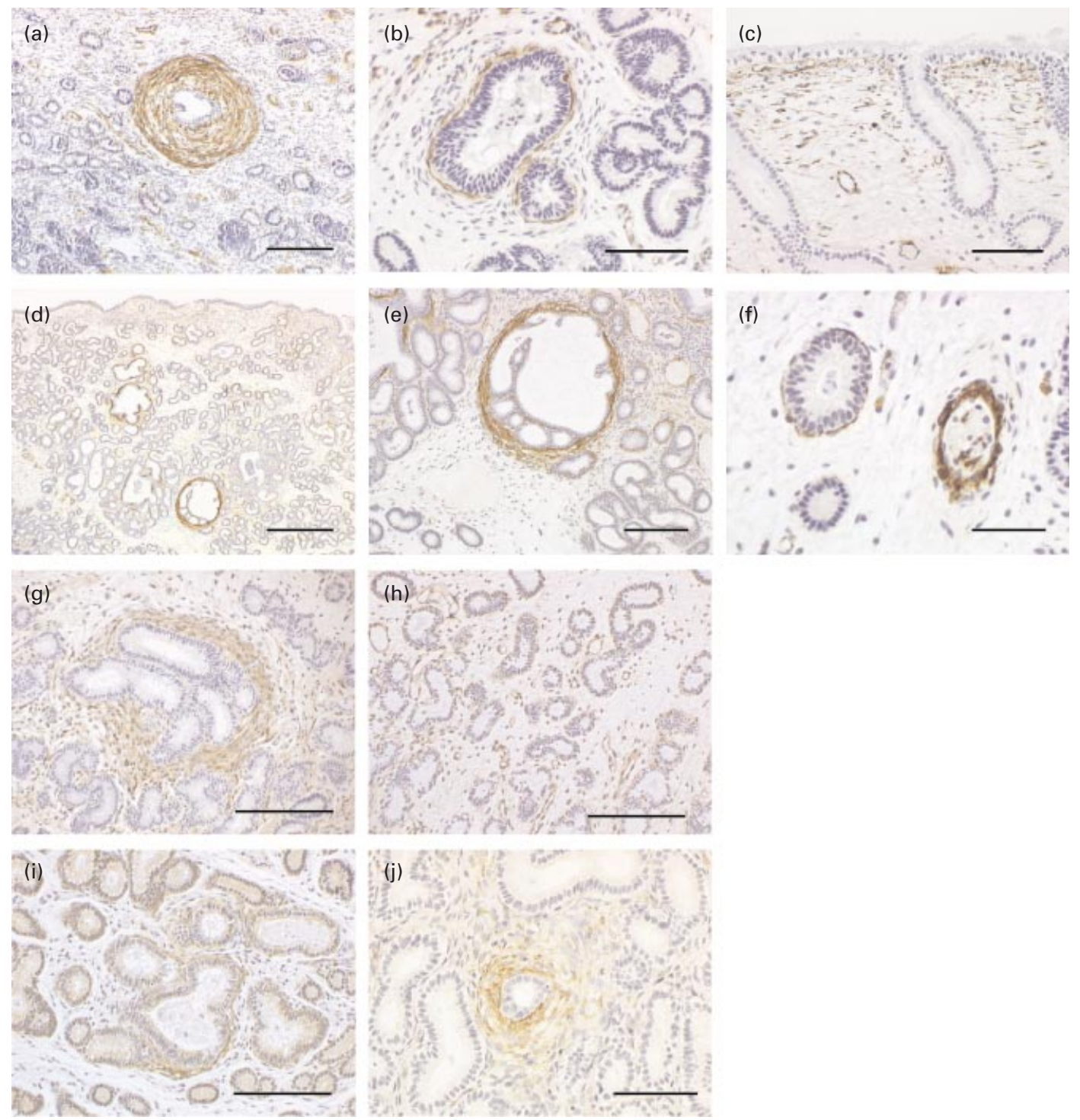

Fig. 2. Immunohistochemical staining for $\alpha$-smooth muscle actin $\alpha$-SMA in the equine endometrium. Note the variable distribution of $\alpha$-SMA positive cells: (a) in thick periglandular sheaths around fibrotic glands, (b) limited to the inner layer of fibrosis, (c) in the stratum compactum, (d,e) distinct immunolabelling of fibrotic, cystic glands, or ( $f$ ) a single layer of cells around histologically inconspicuous uterine glands. Fibronectin expression was demonstrated immunohistochemically around fibrotic uterine glands in endometrotic specimens (g) and in the normal equine endometrium (h). Tropomyosin (i) and desmin (j) were observed in some cases in fibrotic regions. Scale bars represent (a,c,e,f,g,h,i) $100 \mu \mathrm{m}$, (b,j) $50 \mu \mathrm{m}$, (d) $200 \mu \mathrm{m}$.

variable: single uterine glands or gland branches that were highly fibrotic, but not dilated, were cuffed by a thick layer of circularly arranged fibroblasts expressing $\alpha$-smooth muscle actin (Fig. 2a). In addition, cystic dilated glands were coated by a distinct layer of cells positive for $\alpha$-smooth muscle actin (Fig. 2b,d,e). In some cases of thick fibrotic periglandular sheath, only the layer next to the glandular epithelium was positive for $\alpha$-smooth muscle actin (Fig. 2b). In mild cases of endometrosis (category IIA), single cells positive for $\alpha$-smooth muscle actin were arranged closely around the glandular epithelium of histologically incon- spicuous (non-fibrotic, not dilated) glands (Fig. 2f). In single specimens, fibrocytes of the stratum compactum were also shown to express $\alpha$-smooth muscle actin (Fig. 2c), a characteristic not correlated with a particular stage of the oestrous cycle. The deeper connective tissue in the normal endometrium as well as that in endometrotic specimens was free of cells positive for $\alpha$-smooth muscle actin. Smooth muscle cells of blood vessels and the myometrium were positive.

Fibronectin staining was weak although distributed evenly throughout the uterine stroma. Basement membranes 
and endothelia of blood vessels showed intense immunostaining in normal endometrial specimens (Fig. 2h). Highly fibrotic uterine glands were encircled with layers of stromal cells positive for fibronectin (Fig. $2 \mathrm{~g}$ ).

In endometrotic tissue, periglandular fibroblasts expressing $\alpha$-smooth muscle actin were often also immunoreactive for tropomyosin (Fig. 2i), but only a few of the fibroblasts showed co-expression of smooth muscle-specific desmin (Fig. 2j).

\section{Discussion}

In the present study, alterations of stromal cells in the uterine lamina propria were compared between horses with endometrosis and healthy horses. Distribution of ECM proteins (collagen type I, III and IV, fibronectin and laminin) was examined in uterine biopsy samples. There are no reports concerning the distribution of different types of collagen during the oestrous cycle in the normal horse endometrium. Therefore, the present study is the first to demonstrate physiological formation and distribution of collagen fibres in the normal equine endometrium. Immunohistochemical staining demonstrated that the distribution of collagen type I was dependent on the stage of the oestrous cycle, as also observed in cows (Boos, 1994). During the proliferative phase, collagen type I fibres were distributed loosely in the connective tissue due to the excessive oedema present at this stage of the oestrous cycle. At the same time, collagen fibres remained densely arranged in the subepithelial stratum compactum, indicating smaller amounts of interstitial fluid in the subepithelial region. During the secretory phase, collagen type I fibres were densely packed in the whole lamina propria due to the diminished oedema during dioestrus. Fibrillar collagen types I and III, which are the major components of the stromal uterine tissue, did not increase in fibrotic areas in mares that had endometrosis. These findings are in contrast to those of Evans et al. (1998), who observed that endometrosis in horses was correlated with an increase in endometrial periglandular collagen volume fraction, as demonstrated by picrosirius red staining. These contradictory results may be due to the different staining methods used. Blanchard et al. (1987) referred to the limited usefulness of a collagen-specific stain (Masson's trichrome) to enhance visualization of endometrial stromal collagen.

In the present study, immunohistochemistry revealed that collagen IV, normally restricted to the basement membrane, was also present around stromal cells in periglandular fibrosis of single glands and glandular nests, a characteristic of endometrosis. A similar distribution pattern was observed after immunohistochemical staining for laminin, but only in severe cases of fibrosis. Periglandularly arranged fibroblasts in endometrotic specimens were further characterized so that these deposits of ECM could be interpreted. Immunohistochemical staining elucidated that these mesenchymal cells expressed $\alpha$-smooth muscle actin indicating myofibroblastic differentiation. Evans et al.
(1998) showed myofibroblast features of periglandular cells in endometrotic tissue by transmission electron microscopy. Myofibroblasts are known to build up an incomplete layer of basal lamina on their cell surface, which explains the presence of collagen IV and laminin in these regions. These components of the basal lamina are known to maintain smooth muscle cells in a differentiated stage (Schmitt-Gräf et al., 1994). In addition, these cells were frequently found to be positive for tropomyosin and occasionally they showed co-expression of desmin, indicating a smooth muscle cell-like differentiation and contractile potential of these periglandularly arranged cells. Differentiation of periglandular cells to myofibroblasts was also reported for fibrotic dilated glands of the human endometrium (Czernobilsky et al., 1993) leading to a comparable histopathology. It is well known that local stimuli induce smooth muscle differentiation in resident fibroblasts. These stimuli can be produced by neighbouring epithelial or mesenchymal cells (Schmitt-Gräf et al., 1994). However, in the case of equine endometrosis, further investigations are necessary to identify the signals and emitting cells that are responsible for myofibroblast differentiation (and for periglandular fibrosis). Czernobilsky et al. (1993) interpreted periglandular tissue remodelling as a reaction to support the hindered extrusion of secretions. In endometrotic specimens, cystic dilated glands are frequently filled with secretions and cellular debris; therefore, the hindered extrusion of secretions may be the primary reason for their dilation. However, glands that were not dilated, but were highly fibrotic, were frequently observed in endometrotic specimens. These glands were surrounded by cells positive for $\alpha$-smooth muscle actin, although the function of these cells remains unclear. Immunostaining for $\alpha$-smooth muscle actin was also positive around glands that did not appear to be fibrotic by histological examination. This finding could be helpful for the characterization of biopsy samples in a very early stage of endometrosis or to determine horses with a predisposition to the disease.

In highly fibrotic regions of the horse endometrium, fibronectin was present indicating that it has been deposited by stromal cells expressing $\alpha$-smooth muscle actin. This finding supports observations in the present study of deposition of basement membrane components by periglandular stromal cells, as fibronectin is known to be an extrinsic component of the basement membrane produced by connective tissue cells (Flug and Köpf-Meier, 1995). Weak reactivity for anti-fibronectin was frequently present in the stroma and in the blood vessels of the normal equine endometrium which is comparable to data from baboons (Fazleabas et al., 1997). $\alpha$-Smooth muscle actin has also been found in the stroma of benign and malignant epithelial tumours and, therefore, is considered to be a marker for neoplastic lesions (Sappino et al., 1988). Pujuguet et al. (1996) showed that fibronectin is deposited by cancer cells and tumour-associated myofibroblasts. Although further development of endometrosis to benign or malignant 
tumours is not known in horses, it is assumed that periglandular stromal cells are highly active in cases of fibrosis.

In the present study, it was demonstrated that periglandular fibrosis in endometrotic tissue is not characterized by an increased incidence of collagen fibres, but by periglandularly arranged fibroblasts in one or more layers, which produce the ECM proteins collagen IV, laminin and fibronectin. In addition, these fibroblasts express $\alpha$-smooth muscle actin, tropomyosin and occasionally desmin, which confirms their differentiation into smooth muscle-like cells. It remains to be elucidated whether the differentiation of fibroblasts into myofibroblasts has further consequences on the uterine gland epithelium or the stromal cells, as has been shown for various pathological processes. Myofibroblasts are able to produce cytokines, for example interleukins (Zhang et al., 1996); therefore, these cells could be involved in the stimulation of ECM production and degradation which are known to be cytokine-controlled. The immunohistochemical identification of cells positive for $\alpha$-smooth muscle actin might help to evaluate preneoplastic lesions. Further characterization of mechanisms responsible for the observed fibroblastic modulations may be the key to exploring the pathological mechanisms leading to equine endometrosis.

The expert technical assistance of M. Helmreich and B. Machac is greatly acknowledged.

\section{References}

Aplin JD, Charlton AK and Ayad S (1988) An immunohistochemical study of human endometrial extracellular matrix during the menstrual cycle and first trimester of pregnancy Cell and Tissue Research 253 231-240

Behrens C, Aurich JE, Klug E, Naumann H and Hoppen HO (1993) Inhibition of gonadotrophin release in mares during the luteal phase of the oestrous cycle by endogenous opioids Journal of Reproduction and Fertility 98 509-514

Berndt A, Kosmehl H, Katenkamp D and Tauchmann V (1994) Appearance of the myofibroblastic phenotype in Dupuytren's disease is associated with a fibronectin, laminin, collagen type IV and tenascin extracellular matrix Pathobiology 62 55-58

Bissell MJ, Hall HG and Parry G (1982) How does the extracellular matrix direct gene expression? Journal of Theoretical Biology 99 31-68

Blanchard TL, Garcia MC, Kintner LD and Kenney RM (1987) Investigations of representativeness of a single endometrial sample and the use of trichrome staining to aid in the detection of endometrial fibrosis in the mare Theriogenology 28 445-450

Boos A (1994) Immunohistochemical demonstration of collagen types I, III, $\mathrm{IV}, \mathrm{V}$ and $\mathrm{VI}$ in the bovine endometrium during estrous cycle and after superovulation Anatomia Histologia Embryologia 2364
Czernobilsky B, Remadi S and Gabbiani G (1993) Alpha-smooth muscle actin and other stromal markers in endometrial mucosa Virchows Archiv A 422 313-317

Evans TJ, Miller MA, Ganjam VK, Niswender KD, Ellersieck MR, Krause WJ and Youngquist RS (1998) Morphometric analysis of endometrial periglandular fibrosis in mares American Journal of Veterinary Research 59 1209-1214

Fazleabas AT, Bell SC, Fleming S, Sun J and Lessey BA (1997) Distribution of integrins and the extracellular matrix proteins in the baboon endometrium during the menstrual cycle in early pregnancy Biology of Reproduction $\mathbf{5 6}$ 348-356

Flug $\mathbf{M}$ and Köpf-Meier P (1995) The basement membrane and its involvement in carcinoma cell invasion Acta Anatomica 152 69-84

Goranova V, Vizza E and Motta PM (1993) Collagen fibrillar network in estrous and hCG stimulated rabbit uterus: a SEM study after $\mathrm{NaOH}$ maceration Archives of Histology and Cytology $\mathbf{5 6}$ 231-241

Hanamura N, Yoshida T, Matsumoto E, Kawarada Y and Sakakura T (1997) Expression of fibronectin and tenascin-c mRNA by myofibroblasts, vascular cells and epithelial cells in human colon adenomas and carcinomas International Journal of Cancer 73 10-15

Kaidi R, Brown PJ, David JSE, Etherington DJ and Robins SP (1991) Uterine collagen during involution in cattle Matrix 11 101-107

Kenney RM and Doig PA (1986) Equine endometrial biopsy. In Current Therapy in Theriogenology pp 723-729 Eds DA Morrow and WB Saunders. WB Saunders Co., Philadelphia

Koukoulis GK, Howeedy AA, Korhonen M, Virtanen I and Gould VE (1993) Distribution of tenascin, cellular fibronectins and integrins in the normal, hyperplastic and neoplastic breast Journal of Submicroscopic Cytology and Pathology 25 285-295

Pujuguet P, Hammann A, Moutet M, Samuel JL, Martin F and Martin M (1996) Expression of fibronectin ED-A+ and ED-B+ isoforms by human and experimental colorectal cancer. Contribution of cancer cells and tumor associated myofibroblasts American Journal of Pathology 148 579-592

Sappino AP, Skalli O, Jackson B, Schürch W and Gabbiani G (1988) Smooth muscle differentiation in stromal cells of malignant and nonmalignant breast tissues International Journal of Cancer 41 707-712

Sappino AP, Schürch W and Gabbiani G (1990) Biology of disease. Differentiation repertoire of fibroblastic cells: expression of cytoskeletal proteins as a marker of phenotypic modulations Laboratory Investigation $63144-161$

Schmitt-Gräf A, Desmoulière A and Gabbiani G (1994) Heterogeneity of myofibroblast phenotypic features: an example of fibroblastic cell plasticity Virchows Archiv 425 3-24

Schoon HA, Schoon D and Klug E (1997) The endometrial biopsy in the mare with regard to clinical correlations Pferdeheilkunde 13 453-464

Stenback F (1989) Collagen type III formation and distribution in the uterus: effects of hormones and neoplasm development Oncology 46 326-334

Walter I, Klein M, Handler J, Aurich JE, Reifinger M and Aurich C Lectin binding patterns of uterine glands are altered in mares with endometrosis American Journal of Veterinary Research (in press)

Zhang S, Howarth PH and Roche R (1996) Cytokine production by cell cultures from bronchial subepithelial myofibroblasts Journal of Pathology 180 95-101

Received 23 June 2000.

First decision 8 September 2000.

Accepted 13 November 2000. 